\title{
Comunicação
}

[Communication]

\section{Infestação de Tunga penetrans siphonaptera: Tungidae em cascos de vacas leiteiras F1 Holandês-Zebu}

\author{
[Infestation of Tunga penetrans siphonaptera: Tungidae in hooves of F1 Holstein-Zebu cows] \\ J.C.V.C. Ribeiro ${ }^{1}$, S.C. Coelho ${ }^{2 *}$, J.R.M. Ruas $^{3}$, A.M.Q. Lana $^{2}$, A.U. Carvalho ${ }^{2}$ \\ E.J. Facury Filho' ${ }^{2}$, H.M. Saturnino ${ }^{2}$, R.B. Reis ${ }^{2}$ \\ ${ }^{1}$ Ministério da Agricultura, Pecuária e Abastecimento - Brasília, DF \\ ${ }^{2}$ Escola de Veterinária - UFMG \\ Caixa Postal 567 \\ 30123-970 - Belo Horizonte, MG \\ ${ }^{3}$ EPAMIG - Felixlândia, MG
}

\begin{abstract}
A ocorrência de lesões de cascos causadas por Tunga penetrans, uma pulga da família Tungidae, que mede cerca de $1 \mathrm{~mm}$ tem sido descrita na literatura. De acordo com Feldmeier et al. (2004), a fêmea dessa espécie, após a fertilização, introduz-se na pele do hospedeiro, mantendo o ápice do abdômen em comunicação com o exterior. Uma vez instalada, inicia a sucção de sangue para o desenvolvimento dos ovos, ocasião em que seu abdômen pode alcançar o diâmetro de $1 \mathrm{~cm}$. Após a postura total, a fêmea deixa o local por encolhimento ou é expelida pela ulceração. Dos ovos que caem no solo eclodem as larvas que, em torno de 25 dias, dão origem aos insetos adultos.
\end{abstract}

A infestação por $T$. penetrans provoca uma reação inflamatória pruriginosa e dolorida. Feldmeier et al. (2002) encontraram uma grande diversidade de bactérias aeróbicas e anaeróbicas em culturas obtidas de ferimentos causados por $T$. penetrans, dentre estas Clostridium tetani. Silva et al. (2001) examinaram 550 bovinos da raça Girolanda no estado de Goiás, de junho a setembro de 1998, e constataram que $68 \%$ apresentavam lesões características da coronite parasitária. Mauchle (2001) verificou, em uma propriedade do município de Pedro Leopoldo, no período seco do ano, 10,5\% de cascos de bovinos infestados por esse parasita. Souza (2002), ao avaliar vacas da bacia leiteira de Pedro Leopoldo, MG, encontrou 2,5\% dos cascos examinados infestados por T. penetrans.

Recebido em 24 de fevereiro de 2006

Aceito em 12 de fevereiro de 2007

*Autor para correspondência (corresponding author)

E-mail: sandra@vet.ufmg.br

Apoio: FAPEMIG / CAG 350/04
O objetivo deste trabalho foi relatar a infestação de $T$. penetrans em cascos de vacas leiteiras, no período de confinamento/seca.

Em um rebanho F1 Holandês-Zebu, com 170 vacas em lactação, no município de Felixlândia, MG, durante a estação seca (julho de 2004), observou-se a presença de $T$. penetrans, em 130 animais confinados. No período de pastejo foram observadas marcas cicatriciais oriundas desse parasitismo em alguns animais, porém não foi encontrado nenhum parasito. A freqüência de infestação por esse artrópode, no período de confinamento, segundo a ordem de parição encontra-se na Tab. 1.

Apesar da alta infestação e da reação de dor quando da palpação, nenhuma vaca apresentou claudicação. A alta taxa de infestação encontrada e as lesões erosivas (Fig. 1A, B e C) formadas por esses parasitos demonstram a necessidade de se adotar medidas profiláticas durante o período seco do ano. A proliferação descontrolada desse artrópode pode trazer conseqüências indesejáveis de ordem epidemiológica.

Os resultados deste estudo revelaram taxas de infestação mais altas que as relatadas por Silva (2001) em Goiás, Mauchle (2001) e Souza (2002) em Minas Gerais. Alguns dos sifonápteros coletados neste experimento chegaram a medir $1 \mathrm{~cm}$ de diâmetro (Fig. 1D). 
Infestação de Tunga penetrans...

Tabela 1. Freqüência de $T$. penetrans em membros torácicos e pélvicos de vacas $\mathrm{F} 1$ Holandês-zebu, segundo a ordem de parição, durante o período de confinamento, Felixlândia, MG

\begin{tabular}{cccc}
\hline $\mathrm{N}^{\mathrm{o}}$ animais & Ordem de parto & Membros torácicos & Membros pélvicos \\
\hline 70 & $1^{\mathrm{a}}$ cria & $90,51 \mathrm{~b}$ & $96,87 \mathrm{a}$ \\
30 & $2^{\mathrm{a}}$ cria & $95,31 \mathrm{~b}$ & $100,00 \mathrm{a}$ \\
30 & $>2^{\mathrm{a}}$ cria & $100,00 \mathrm{a}$ & $100,00 \mathrm{a}$ \\
\hline
\end{tabular}

Médias seguidas por letras distintas na linha diferem entre si pelo teste qui-quadrado $(\mathrm{P}<0,05)$.
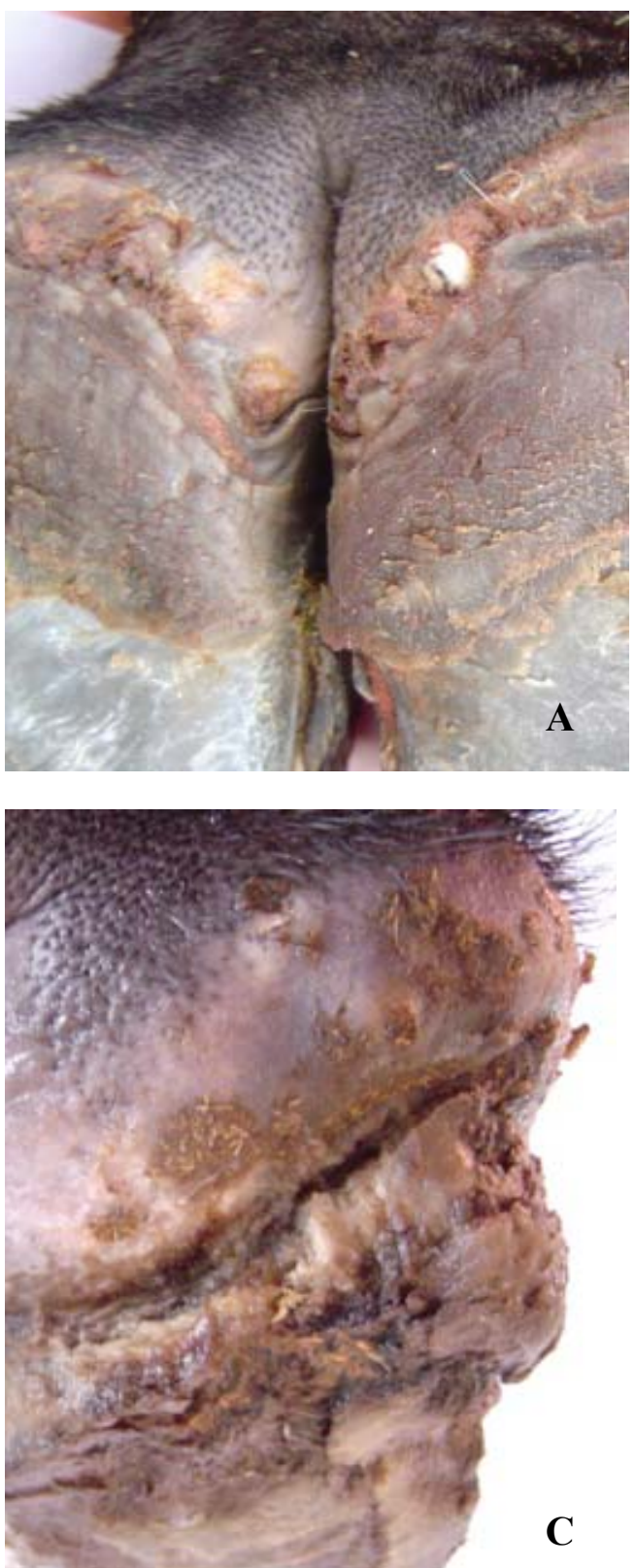
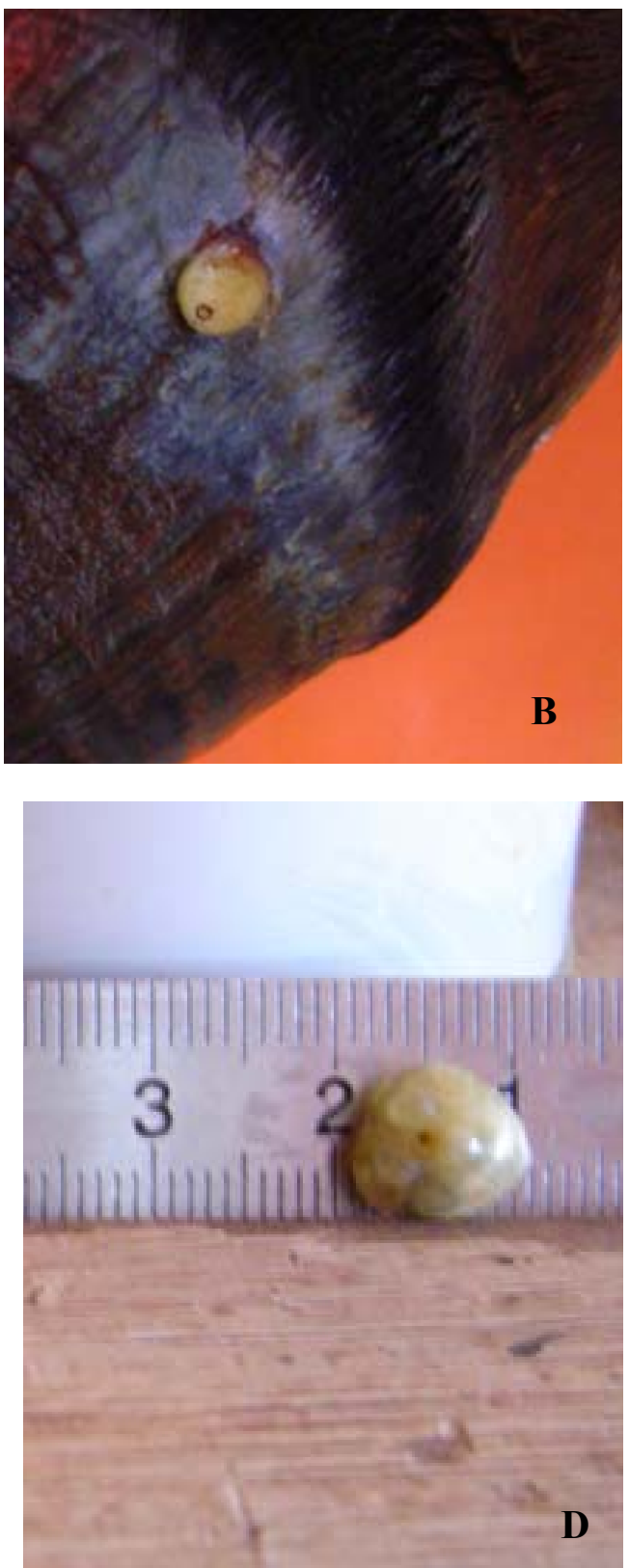

D

Figura 1. Lesões por Tunga penetrans em cascos de vacas. A - T. penetrans alojada no talão; B - coronite parasitária grave; $\mathrm{C}$ - Coronite parasitária grave; $\mathrm{C}-T$. penetrans $(1 \mathrm{~cm})$. 
Verificou-se, na propriedade estudada, uma alta freqüência de $T$. penetrans, com acometimento de quase a totalidade das vacas em lactação, que estavam confinadas durante o período seco do ano. Essa alta freqüência de coronite parasitária pode ter conseqüências graves, como infecções secundárias e manqueiras. Medidas de controle devem ser adotadas nesta propriedade para manter a integridade dos cascos de bovinos no período seco do ano.

Palavras-chave: vaca leiteira, cascos, Tunga penetrans, freqüência

\begin{abstract}
Tunga penetrans rate of infestation in hooves of confined F1 Holstein-Zebu cows during the dry season was recorded. First parturition cows showed an infestation rate of $90.5 \%$ in the thorax and 96.9 in the pelvic members, second parturition cows showed an infestation rate of $95.3 \%$ in the thorax and $100 \%$ in the pelvic members while third parturition cows showed rate of infestation of $100 \%$ for both members.
\end{abstract}

Keywords: dairy cow, hooves, Tunga penetrans, frequency

\section{REFERÊNCIAS BIBLIOGRÁFICAS}

FELDMEIER, H.; EISELE, M.; MARCK, E. et al. Investigations on the biology, epidemiology, pathology and control of Tunga penetrans in Brazil: IV. Clinical and histopathology. Parastiol. Res., v.94, p.275-282, 2004.

FELDMEIER, H.; HEUKELBACH, J.; EISELE, M. Bacterial superinfection in human tungiasis. Trop. Med. Int. Health, v.7, p.559-564, 2002.

MAUCHLE, U. Afecções podais e conformação dos cascos em bovinos. 2001. 80f. Dissertação (Mestrado) - Escola de Veterinária, Universidade Federal de Minas Gerais, Belo Horizonte.
SILVA, L.A.F.; SANTANA, A.P.; BORGES, G.T. et al. Aspectos epidemiológicos e tratamento da tungiase bovina no município de Jataí, estado de Goiás. Cien. Anim. Bras., v.2, p.65-67, 2001.

SOUZA, R.C. Perfil epidemiológico e clínico das afecções podais em vacas nas bacias leiteiras de Belo Horizonte e Pedro Leopoldo. 2002, 72f. Dissertação (Mestrado) - Escola de Veterinária, Universidade Federal de Minas Gerais, Belo Horizonte. 